\title{
Retrieval of Pups by Female Rats Undernourished during the Pre- and Neonatal Period
}

\author{
Judith Felix, Mirelta Regalado, Carmen Torrero, Manuel Salas \\ Department of Developmental Neurobiology and Neurophysiology, Institute of Neurobiology, Universidad \\ Nacional Autónoma de México, Campus UNAM Juriquilla, Querétaro, México \\ Email: masal@unam.mx
}

Received 23 May 2014; revised 6 July 2014; accepted 17 July 2014

Copyright @ 2014 by authors and Scientific Research Publishing Inc.

This work is licensed under the Creative Commons Attribution International License (CC BY). http://creativecommons.org/licenses/by/4.0/

c) (i) Open Access

\begin{abstract}
Early mother-litter bonds alterations elicited by pre- and neonatal undernutrition are a source of long-lasting brain and functional disorders such as exploratory and emotional deficits and maternal unresponsiveness to the newborn. Here, we examined the prolonged effects of gestational and neonatal food restriction on the retrieval of pups and nest building activity by primiparous adult Wistar rats on postnatal days (PDs) 4, 8, and 12. In early undernourished dams, the latency to retrieve the first or the fifth pups in the litter was extended; and nest building activity was significantly reduced. Additionally, early underfed dams retrieved the pups in a rough manner, eliciting distress cries and grasping the pups by unusual body areas. The current findings suggest that preand neonatal food restriction may affect the anatomical and functional forebrain structures, modulating the cognitive and motor components underlying maternal responsiveness.
\end{abstract}

\section{Keywords}

Perinatal Undernutrition, Retrieval of Pups, Stressed Dams

\section{Introduction}

In altricial species the maternal response is fundamental for newborn survival, interactions with the mother and environmental cues in the nest stimulate the normal brain developmental processes and promote subsequent brain plasticity changes that may have a variety of long-term anatomical and functional consequences. Maternal behavior in the rat is initiated by a gradual decrease of progesterone from high levels at mid-gestation and an increase in estradiol and prolactin levels; after birth, maternal responsiveness depends primarily on the pup's de- 
mands in the context of the nest environment [1]. Previous studies have shown that different paradigms of neonatal undernutrition or malnutrition in the rat produce severe alterations in the maternal response of adult lactating dams, including deficiencies in nest building, licking of pups, nursing time, and retrieval of the young [2]-[5]. Most of these long-term behavioral alterations result from an interference with programming of the hypothalamic-hypophysial axis that results in defects in activating hormonal targets [6]. These behavioral deficiencies of early underfed dams correlate well with their brain alterations in myelination, dendritic arbor growth, and the synaptic organization of the neuronal sensory systems, alterations that seriously interfere with the mother-litter interactions and cause functional deficiencies and brain disorders throughout the lifespan of the progeny [4] [7][13].

The maternal circuitry normally acquires neuronal plasticity during gestation and lactation; this unique CNS property involves through hormonal and sensory mechanisms and specific synaptic and functional changes in the medial preoptic area, prefrontal, medial, and dorsolateral cortices; the anterior cingulated gyrus, and the amygdala to improve and adapt the dam's responsiveness to the pup's demands that are essential for their survival and growth [1] [14]-[17].

The current study analyzed the long-term effects of perinatal undernourishment (PU) on the mother-litter bonds: these effects reflect deficient plasticity of the maternal circuitry and include reduced nest building, prolonged retrieval latency, abnormal site of grasping pups for transportation, and pup vocalizations during the maternal retrieval. Our interest in the maternal response components arose from previous studies in which we found that neonatal undernutrition significantly reduces the magnitude of these normal behavioral components [4] [5].

\section{Material and Methods}

\subsection{Subjects}

Animals were female Wistar rats (Rattus norvegicus) and the first-litters descendants of a stock originally obtained from Harlan Sprague-Dawley, Indianapolis, USA. The subjects were born and bred in the animal care facility at the Neurobiology Institute, University of Mexico. They were maintained at a temperature of $24^{\circ} \mathrm{C} \pm 2^{\circ} \mathrm{C}$ and 50\% humidity on a $12 \mathrm{hr} / 12 \mathrm{hr}$ light/dark cycle (lights on at $0700 \mathrm{hr}$ ), with water and food (Purina chow) ad lib. For mating, two males were placed in a plastic cage containing four virgin females (200 - $250 \mathrm{~g})$. Spermpositive females were placed individually in plastic maternity cages $\left(50 \times 30 \times 20 \mathrm{~cm}^{3}\right)$ with grill tops and wood shavings as nesting material one week before parturition. The day of birth was referred to as postnatal day 0; 24 hr later pups were weighed and sexed, and five females and five males from each litter were randomly distributed among dams in order to minimize genetic and nutritional differences that may influence the experimental results. The presence of the bilateral thoracic and abdominal line of nipples and the shorter anogenital distance in the females were used as criteria for sex recognition [18]. Animal care and protocols were approved by local Animal Committees and were consistent with the NRC Guide for the Care and Use of Laboratory Animals [19].

\subsection{Nutritional Procedures}

\subsubsection{Control Group (CG)}

The CG animals were 12 female pups obtained from five litters normally nourished by well-fed mothers with free access to food and water during the gestation and lactating periods. After birth, pups were fed and handled by interchanging a pair of normally lactating mothers every $12 \mathrm{hr}$ for 24 days as previously described [20]. The female rats obtained by this procedure were mated and maternally tested as adults.

\subsubsection{Underfeed Group (UG)}

The UG females $(\mathrm{n}=12)$ came from at least five different litters. The normal chow diet requirement was calculated by measuring the food intake of a group of 6 pregnant control rats (200 - 250 g) every week during a 21day period. The resulting average food intake for each week was the basal level used to calculate the food-intake percentage of the UG females. Thus, dams were fed from gestational day 6 (G6) to G12 with 50\% (7.8 g) of the normal diet (Purina chow), from G13 to G19 with 70\% (10.9 g), and then with 100\% (15.6 g) of the same diet until parturition to avoid resorption or cannibalism of pups. This protocol was chosen because neurogenesis of the cortical and subcortical maternal circuit and afferent connectivity occur primarily from G16 to G21 [21]. At birth, prenatally underfed female newborns were nursed by two, gestationally underfed dams, in one of which 
the main galactophorous ducts had been tied subcutaneously. The two lactating dams were interchanged every $12 \mathrm{hr}$ between litters from postnatal days 1 to 23. Both experimental groups were weaned at 25 days of age, after which rats were allowed free access to water and food (Purina chow) (Figure 1). The females were maintained in groups of 4 - 6 until reaching 90 - 100 days of age, when they were mated and tested for maternal behavior with their own litter. This cross-fostering procedure ameliorates the effects on the pups of maternal sensory deprivation [20]. No attempts were made to measure food intake in pregnant dams or newborn female rats. Approximately $80 \%$ of the total PU subjects included here were undernourished during the light phase of the cycle. To evaluate the effects of the different nutritional paradigms on physical growth, body weights of dams at gestational day 21, and of the pups at PDs 1, 4, 8, and 12 were noted.

\subsection{Behavioral Testing}

A total of 24 dams (12 control and 12 undernourished) were tested for maternal behavior in their own plastic living cages at 90 days of age. Approximately 3 days before parturition, nulliparous females were placed in translucent plastic maternity cages $\left(20 \times 40 \times 60 \mathrm{~cm}^{3}\right)$ and provided with wood shavings as bedding. Twentyfour hours after parturition each litter was culled to 10 pups per mother ( 5 males and 5 females). Each mother was given three retrieval tests, one each on days 4,8 , and 12 postpartum, in its own living cage including wood shavings, and with its own litter. The tests were performed between 10:00 and 12:00 hr when maternal care is highly expressed [22]-[25]. This test was performed on three days only, to minimize the disruption of motherinfant bonds. The behavioral tests were videotaped $(10 \mathrm{~min})$ in a sound-proof chamber next to the main laboratory under continuous dim illumination provided by a red light $(60 \mathrm{~W})$. Different litters and pups in a litter were assigned a random number to insure that behavioral measures taken by a rater were blind with respect to their age and treatment, and to the hypothesis of the experiment. Furthermore, the retrieval latency to the first and the fifth pup in the litter by the dam measurements were compared to the counts obtained in at least two other litters per group, randomly chosen by another experimenter. A score of 1 was assigned to gentle pup transportation and 2 to a rough type, and vocalizations were noted.

At the end of the retrieval test, nest building was evaluated as another sign of maternal care. The nest was scored on the basis of its shape and dimensions. A score of 3 was assigned to a round, well-made nest approximately 3 - $4 \mathrm{~cm}$ in height; 2 , to a partially destroyed oval nest; and 1 , to a nearly destroyed nest of amorphous shape.

\subsection{Statistics}

Experimental data were analyzed with the Systat Statistical Package version 7.0. To compare differences in body weight of dams and pups, maternal retrieval, nest building, ages, and dietary treatments, the following separate statistical analyses were used: 1) body weight scores of pups nursed by control or perinatally underfed dams were compared in a two-way ANOVA, 2 (nutritional regimes), with repeated measures in one factor 4 (ages); 2) separate latencies to retrieve the first and the fifth pup on three postpartum days, and nest building of dams were analyzed by a two-way ANOVA, 2 (nutritional regimes) $\times 3$ (ages) in both cases with repeated measures in the

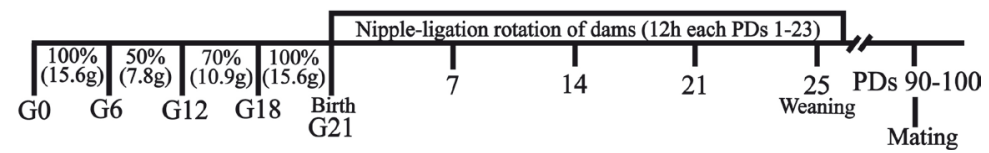

(a)

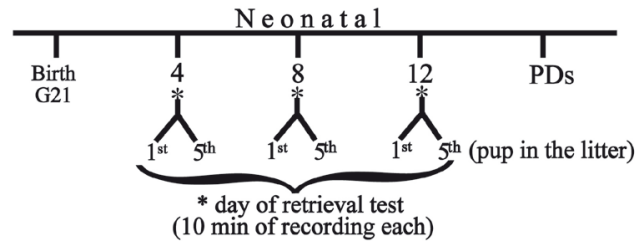

(b)

Figure 1. Experimental design for underfeeding and maternal evaluation. (a) Underfeeding method; (b) Maternal behavior (retrieval and nest building). 
age factor; 3) to compare the probability of grasping body areas a three-way ANOVA, 2 (nutritional regimes) $\times 4$ (ages) $\times 6$ (body areas) was used; 4) rough transportation of pups by 12 dams per experimental condition at the three ages tested was analyzed with a two-way ANOVA 2 (nutritional regimes) $\times 3$ (ages) with repeated measures in the age factor. Comparisons of scores between the nutritional regimes over time were made using the Fisher LSD post hoc test. The threshold level for significance was set at $p<0.05$.

\section{Results}

\subsection{Effects on Body Weight}

The ANOVA comparisons of the body weight scores between the CG and the UG dams at gestational day 21 yielded a significant effect of diet, $\mathrm{F}(1,22)=33.72, p<0.0001$. After birth the UG dams weighed significantly less than CG mothers, $\mathrm{F}(1,22)=28.96, p<0.00002$, with a significant effect of age, $\mathrm{F}(3,66)=21.38, p<$ 0.00001 , and without interaction between factors. Body weights of dams in both experimental groups at postnatal days (PDs) 1, 4, 8, and 12 showed a slight increase although the values for the UG were significantly lower than those of the CG subjects $(p<0.01)$. The ANOVA comparisons of the pups body weight score between CG and the UG along the ages indicated significant effects of the diet, $\mathrm{F}(1,198)=6.56, p<0.01$, and the age factor, $\mathrm{F}(3,594)=583.21, p<0.0001$ without interactions between factors. Furthermore, newborn body weights measured on PDs $1,4,8$, and 12 were significantly reduced $(p<0.05)$ only on PD 12 (Table 1 ).

\subsection{Effects on the Maternal Response}

\subsubsection{Effects on the Retrieval Latency}

The ANOVA comparisons between groups showed that underfed dams were significantly slower in retrieving the first of the pups compared to the UG mothers, $\mathrm{F}(1,44)=10.61, p<0.003$; this was affected by the retrieval day, $\mathrm{F}(2,44)=3.74, p<0.03$, but without interactions between factors. The latency to retrieve the fifth pup was also longer in the UG dams, $\mathrm{F}(1,44)=34.96, p<0.00006$; it was also modified by the retrieval day, $\mathrm{F}(2,44)=$ $10.94, p<0.0001$, and there was a significant interaction between the diet $\times$ age factors, $\mathrm{F}(2,44)=5.37, p<$ 0.008. Post hoc comparisons for each day of testing showed significantly prolonged $(p<0.05)$ latencies to retrieve the first on PD 12 and the fifth pup in the litter by the UG mothers only on PDs 8 and 12, respectively (Figure 2(a) and Figure 2(b)).

The probability of each area of the pup's body being grasped for the experimental dam on PDs 4, 8, and 12 is based on a sample of 24 measurements of mothers carrying pups on each day, and is shown in Figure 3(a). The dams in the CG grasped pups by the nape of the neck, $\mathrm{F}(1,22)=p<0.0001$ more often than UG dams, and other body areas were rarely chosen; there was also a significant interaction between the diet $\times$ age factors, $\mathrm{F}(2,44)=$ $3.28, p<0.04$. By contrast, UG mothers showed a clear preference for grasping the pups by the anterior or posterior limbs, $\mathrm{F}(1,22)=106.42, p<0.0001$, and the head, $\mathrm{F}(1,22)=p<0.0001$, compared to the CG mothers. The ANOVA comparisons did not indicate significant interactions between the factors. The statistical analysis also showed that during the retrieval test of $12 \mathrm{PU}$ dams, the pups emitted more significant distress vocalizations than controls, $\mathrm{F}(1,44)=39.73, p<0.0002$ on all days of the study. Post hoc comparisons indicated that pups carried by UG dams emitted significantly $(p<0.05)$ more distress vocalizations than those carried by CG dams (Figure 3(b)).

\subsubsection{Effects on Nest Building}

The ANOVA comparisons of the nest scores yielded evidence of deficient nest building activity in the UG dams, $\mathrm{F}(1,44)=12.20, p<0.002$; with changes on the postpartum days, $\mathrm{F}(2,44)=5.27, p<0.0 .008$ and no interaction between factors. The post hoc comparisons on each day of testing indicated significant reductions $(p<0.05)$ in the nest building parameters only on PDs 4, and 8 (Figure 4).

\section{Discussion}

The current findings indicated that in the PU dams the latency to retrieve the first or the fifth of the pups in the litter was significantly prolonged, and the nest-building response was also reduced. Additionally, these early underfed dams retrieved the pups in a rough manner, eliciting distress cries, they grasped the pups by unusual body areas, and showed more non-maternal tail chasing than controls, suggesting the dams had deficits in pup's recognition, visual discrimination, and transport of newborns [4] [5] [7] [11] [12]. These long-term maternal be 
Table 1. Body weight of pups reared by control (CG) and neonatally underfed (UG) dams ( $\mathrm{n}=100)$ during development.

\begin{tabular}{|c|c|c|c|}
\hline \multirow{2}{*}{ Days } & \multicolumn{3}{|c|}{ Body weight } \\
\hline & CG & & UG \\
\hline 1 & $7.10 \pm 0.057$ & & $6.93 \pm 0.091$ \\
\hline 4 & $9.72 \pm 0.091$ & & $9.75 \pm 0.175$ \\
\hline 8 & $15.94 \pm 0.873$ & & $14.93 \pm 0.197$ \\
\hline 12 & $21.21 \pm 0.212$ & & $19.57 \pm 0.363^{*}$ \\
\hline Factor & $\mathrm{df}$ & $\mathrm{F}$ & $p$ \\
\hline Diet (A) & 1,198 & 6.563 & $<0.0110$ \\
\hline Age (B) & 3,594 & 583.211 & $<0.0001$ \\
\hline $\mathrm{A} \times \mathrm{B}$ & 3,594 & 2.415 & NS \\
\hline
\end{tabular}

NS. Non significant, ${ }^{*} p<0.05$, Fisher LSD test.

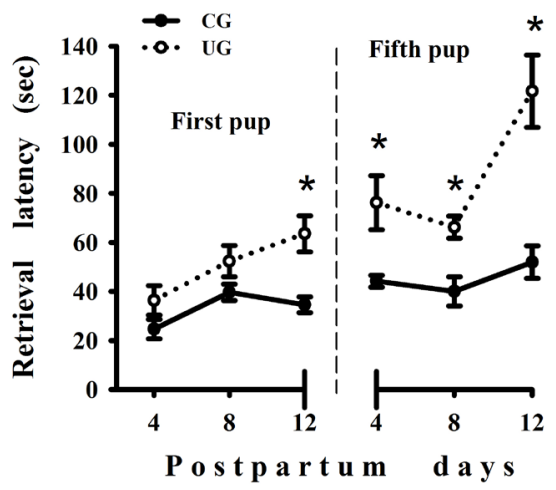

(a)

(b)

Figure 2. Mean latency ( \pm SEM) in seconds, for retrieval of the first (a) and the fifth pup (b) after placing the mother on an empty nest, exhibited by lactating control (CG) and perinatally undernourished (UG) dams. * Statistically significant differences $(p<0.05)$.

havioral alterations may be related to a number of factors occurring during the gestation including the reduced size, and, abnormal structure and function of the placenta that interferes with the nutrient supply to the fetus, its weight, and physical development [26]-[28]. Additionally, perinatal food restriction of the dams during lactation results in significant decreases in the dendritic density, number of spines, and synaptogenesis in the prefrontal and limbic structures that generate, in adulthood, cognitive attentional deficiencies that impair pup retrieval and the nest building response [13] [29]-[32].

Two other factors that might explain the dam's abnormal pup retrieval and nest-building activity observed here are the role of the PU and alterations in the mother-litter-bonds. Previous studies show that early undernutrition or malnutrition in lactating dams seriously interferes with the mother-litter relationships, as indicated by the reduced maternal, anogenital, and fur licking of the pups, the reduced ventrum somatosensory contacts provided to the pups, and less nursing time spent with the litter which impacts the milk secretion. At the same time, the deficient mother-litter bond also affects the newborn brain growth, behavioral development, and stress all of which have been associated with mental disorders at later stages of life [4] [10] [31]-[33].

The fact that PU dams were affected early in life by the current pre- and neonatal-underfeeding paradigms, provides a test of how a mild chronic stress influenced the development of a circuit of prefrontal cortical structures underlying the attentional processes and maternal care of the progeny. In this regard, it is known that different types of undernutrition, and chronic stress situations underlie impairments in the cognitive perceptual attentional and the executive maternal responsiveness to the young, these include separating pups for 6 hr daily in a 


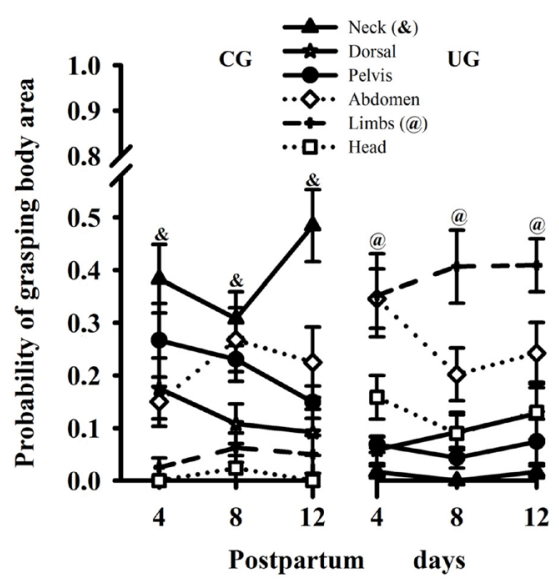

(a)

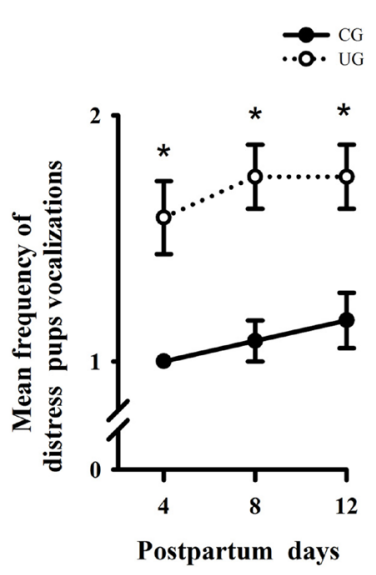

(b)

Figure 3. (a) Probability of control (CG) and perinatally undernourished (UG) dams grasping each of the specific body areas of pups during the retrieval test, based on 12 observations per experimental group of dams on each day of the lactating period; (b) Mean number ( \pm SEM) of distress vocalizations emitted by nursed control and undernourished pups during maternal transport at the three different ages. "Statistically significant differences $(p<0.05)$.

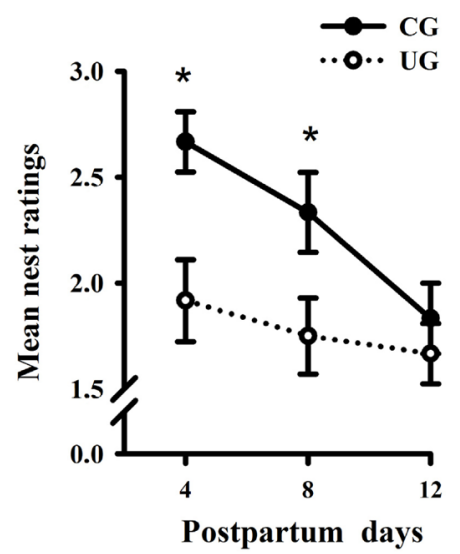

Figure 4. Mean nest-building score $( \pm$ SEM) yielded from lactating control (CG) and perinatally undernourished (UG) dams. *Statistically significant differences $(p<0.05)$.

wire mesh restrainer for 21 days; placing pregnant dams in cylindrical restrainers for 15 to 45 min daily for 23 days postnatally; $12 \mathrm{hr}$ of daily isolation over a 24-hr day span in an incubator, or cytotoxic lesions that provoked reduced apical or basilar dendritic prolongations, spine density, and perikarya pyramidal measurements of layer II/III in the medial prefrontal cortex, dorsal anterior cingulate, and dorsolateral prefrontal cortex [13] [31][34]. The neuronal hypoplasia in the maternal circuitry structures may disrupt the ascending integration of spatiotemporal patterns of coding information needed to regulate the expression of plastic maternal behavior [13]. By contrast when the individual pup's daily separation from the dam is only $1 \mathrm{hr}$, body and brain weights were not significantly different between the underfed and control groups suggesting a differential brain impact related to the time and the intensity of the stress exposure [35].

On the other hand, the disrupted mother-litter interactions of the PU rats tested for maternal behavior in adulthood may reflect a poor nest environment, insufficient tactile and somatosensory stimulation, and interference with the release of different hormones (GH, T4-T3), growth factors (EGF) and the ornithine decarboxylase (ODC) enzyme, all of which influence protein synthesis in the brain and interfere with its physical, and functional development, leading to defects in maternal behavior [10] [36]-[41]. Finally, the maternal response defi- 
cits of early underfed dams may be correlated with functional alterations elicited in neurons during lactation by the low but significant levels of circulating leptin, or with increased plasma levels of glucocorticoids that interfere with the anatomical organization of neurons in the hippocampus and the prefrontal cortices, both of which can impair the behavioral cognitive processes at later ages [42] [43].

\section{Conclusion}

The maternal behavioral deficiencies of dams with PU described here reflect not only the delay in early sensory development, but also the poor mother-litter bonds formed as adults that negatively impact the physical and brain development of the progeny. Our data also suggest that the maternal circuitry plasticity of PU dams occurred during the gestation and lactation was insufficient for the integration of the physiological cognitive processes such as the maternal behavior.

\section{Acknowledgements}

The study was partly supported by DGAPA/UNAM, IN200413. The authors thank Dr. Dorothy Pless for editorial assistance and helpful suggestions.

\section{References}

[1] Rosenblatt, J.S., Mayer, A.D. and Giordano, A.L. (1988) Hormonal Basis during Pregnancy for the Onset of Maternal Behavior in the Rat. Psychoneuroendocrinology, 13, 29-46. http://dx.doi.org/10.1016/0306-4530(88)90005-4

[2] Smart, J.L. and Preece, J. (1973) Maternal Behavior of Undernourished Mother Rats. Animal Behavior, 21, 613-619. http://dx.doi.org/10.1016/S0003-3472(73)80024-7

[3] Massaro, T.F., Levitsky, D.A. and Barnes, R.H. (1974) Protein Malnutrition in the Rat: Its Effects on Maternal Behavior and Pup Development. Developmental Psychobiology, 7, 551-561. http://dx.doi.org/10.1002/dev.420070607

[4] Salas, M., Torrero, C. and Pulido, S. (1984) Long-Term Alterations in the Maternal Behavior of Neonatally Undernourished Rats. Physiology and Behavior, 33, 273-278. http://dx.doi.org/10.1016/0031-9384(84)90111-2

[5] Salas, M., Torrero, C., Regalado, M. and Perez, E. (2002) Retrieving of Pups by Neonatally Stressed Mothers. Nutritional Neuroscience, 5, 399-405. http://dx.doi.org/10.1080/1028415021000055943

[6] Vieau, D. (2011) Perinatal Nutritional Programming of Health and Metabolic Adult Disease. World Journal of Diabetes, 2, 133-136.

[7] Callison, D.A. and Spencer, J.W. (1968) Effect of Chronic Undernutrition and/or Visual Deprivation upon the Visual Evoked Potential from the Developing Rat Brain. Developmental Psychobiology, 1, 196-204. http://dx.doi.org/10.1002/dev.420010308

[8] Salas, M. and Cintra, L. (1973) Nutritional Influences upon Somatosensory Evoked Responses during Development in the Rat. Physiology and Behavior, 10, 1019-1022. http://dx.doi.org/10.1016/0031-9384(73)90182-0

[9] Sima, A. and Sourander, P. (1974) The Effect of Early Undernutrition on the Caliber Spectrum of the Rat Optic Nerve. Acta Neuropathologica, 28, 151-160.

[10] Smart, J.L. (1976) Maternal Behavior of Undernourished Mother Rats Toward Well Fed and Underfed Young. Physiology and Behavior, 16, 147-149. http://dx.doi.org/10.1016/0031-9384(76)90298-5

[11] Galler, J.R., Fleischer, S.F., Turkewitz, G. and Manes, M. (1980) Varying Deficits in Visual Discrimination Performance Associated with Different Forms of Malnutrition in Rats. Journal of Nutrition, 110, 231-240.

[12] Gonzalez, A., Lovic, V., Ward, G.R., Wainwright, P.E. and Fleming, A.S. (2001) Intergenerational Effects of Complete Maternal Deprivation and Replacement Stimulation on Maternal Behavior and Emotionality in Female Rats. Developmental Psychobiology, 38, 11-32. http://dx.doi.org/10.1002/1098-2302(2001)38:1<11::AID-DEV2>3.0.CO;2-B

[13] Torrero, C., Regalado, M., Rubio, L. and Salas, M. (2014) Effects of Neonatal Undernutrition on Development of the Dorsolateral Prefrontal Cortex Pyramidal Cells in the Rat. Journal of Behavioral and Brain Science, 2, 49-57. http://dx.doi.org/10.4236/jbbs.2014.41007

[14] Corodimas, P., Rosenblatt, J.S., Canfield, M.E. and Morrell, J.I. (1993) Neurons in the Lateral Subdivision of the Habenular Complex Mediate the Hormonal Onset of Maternal Behavior in Rats. Behavioral Neuroscience, 107, 827-843. http://dx.doi.org/10.1037/0735-7044.107.5.827

[15] Fleming, A.S., O’Day, D.H. and Kraemer, G.W. (1999) Neurobiology of Mother-Infant Interactions: Experience and Central Nervous System Plasticity across Development and Generations. Neuroscience Biobehavioral Reviews, 23, 673-685. 
[16] Numan, M. and Stolzenberg, D.S. (2009) Medial Preoptic Area Interactions with Dopamine Neural Systems in the Control of the Onset and Maintenance of Maternal Behavior in Rats. Frontiers in Neuroendocrinology, 30, 46-64. http://dx.doi.org/10.1016/j.yfrne.2008.10.002

[17] Kim, P., Leckman, J.F., Mayes, L.C., Feldman, R., Wang, X. and Swain, J.E. (2010) The Plasticity of Human Maternal Brain: Longitudinal Changes in Brain Anatomy During the Early Postpartum Period. Behavioral Neuroscience, 124, 695-700. http://dx.doi.org/10.1037/a0020884

[18] Vanderbergh, J.G. (2003) Prenatal Hormone Exposure and Sexual Variation. American Scientist, 91, 218-225. http://dx.doi.org/10.1511/2003.3.218

[19] NRC National Research Council (2003) Guidelines for the Care and Use of Mammals. In: National Research Council of the National Academies Neuroscience and Behavioral Research, National Academies Press, Washington, 209.

[20] Altman, J. and Bayer, S.A. (1995) Atlas of Prenatal Rat Brain Development. CRC Press, Boca Raton.

[21] Lynch, A. (1976) Postnatal Undernutrition: An Alternative Method. Developmental Psychobiology, 9, 39-48.

[22] Grota, L.J. and Ader, R. (1969) Continuous Recording of Maternal Behavior in Rattus norvegicus. Animal Behavior, 17, 722-729. http://dx.doi.org/10.1016/S0003-3472(69)80019-9

[23] Brewster, J. and Leon, M. (1980) Facilitation of Maternal Transport by Norway Rat Pups. Journal of Comparative Physiology and Psychology, 94, 80-88. http://dx.doi.org/10.1037/h0077645

[24] Olazabal, D.E. and Ferreira, A. (1997) Maternal Behavior in Rats with Kainic Acid-Induced Lesions of the Hypothalamic Paraventricular Nucleus. Physiology and Behavior, 61, 779-784. http://dx.doi.org/10.1016/S0031-9384(96)00567-7

[25] Esposito, G., Yoshida, S., Onhishi, R., Tsuneoka, Y., Rostagno, M.C., Yokota, S., Okabe, S., Kamiya, K., Hosino, M. Shimizu, M., Venuti, P., Kikusui, T. Shimizu, M. and Kuroda, O. (2013) Infant Calming Responses during Maternal Carrying in Humans and Mice. Current Biology, 23, 739-745. http://dx.doi.org/10.1016/j.cub.2013.03.041

[26] Mitra, K. and Chowdhury, M.K. (2002) Maternal Malnutrition, Perinatal Mortality and Foetal Pathology: A Clinicopathological Study. Journal of Indian Medical Association, 100, 85-87.

[27] Wu, G., Bazer, F.W., Cudd, T.A., Meininger, C.J. and Spencer, T.E. (2004) Maternal Nutrition and Fetal Development. Journal of Nutrition, 134, 2169-2172.

[28] Belkacemi, L., Nelson, D.M., Desai, M. and Ross, M.G. (2010) Maternal Undernutrition Influences Placental-Fetal Development. Biology of Reproduction, 83, 325-331. http://dx.doi.org/10.1095/biolreprod.110.084517

[29] Slotnick, B. (1967) Disturbance of Maternal Behavior in the Rat Following Lesions of the Cingulated Cortex. Behaviour, 29, 204-236. http://dx.doi.org/10.1163/156853967X00127

[30] Escobar, C. and Salas, M. (1993) Neonatal Undernutrition and Amygdaloid Nuclear Complex Development: An Experimental Study in the Rat. Experimental Neurology, 122, 311-318. http://dx.doi.org/10.1006/exnr.1993.1130

[31] Liston, C., Miller, M.M., Goldwater, D.S., Radley, J.J., Rocher, A.B., Hof, P.R., Morrion, J.H. and McEwen, B.S. (2006) Stress-Induced Alterations in Prefrontal Cortical Dendritic Morphology Predicts Selective Impairments in Perceptual Attentional Set-Shifting. The Journal of Neuroscience, 26, 7870-7874. http://dx.doi.org/10.1523/JNEUROSCI.1184-06.2006

[32] Febo, M., Felix-Ortiz, A. and Johnson, T. (2010) Inactivation or Inhibition of Neuronal Activity in the Medial Prefrontal Cortex Largely Reduces Pup Retrieval and Grouping in Maternal Rats. Brain Research, 1325, 77-88. http://dx.doi.org/10.1016/j.brainres.2010.02.027

[33] Murmu, M.S., Salomon, S., Biala, Y., Weinstock, M., Braun, K. and Bock, J. (2006) Changes of Spine Density and Dendritic Complexity in the Prefrontal Cortex in Offspring of Mothers Exposed to Stress during Pregnancy. European Journal of Neuroscience, 24, 1477-1487. http://dx.doi.org/10.1111/j.1460-9568.2006.05024.x

[34] Passetti, F., Chudasama, Y. and Robbins, T.W. (2002) The Frontal Cortex of the Rat and Visual Attentional Performance: Dissociable Functions of Distinct Medial Prefrontal Subregions. Cerebral Cortex, 12, 1254-1268. http://dx.doi.org/10.1093/cercor/12.12.1254

[35] Bock, J., Gruss, M., Becker, S. and Braun, K. (2005) Experience-Induced Changes of Dendritic Spine Densities in Prefrontal and Sensory Cortex: Correlation with Developmental Time Windows. Cerebral Cortex, 15, 802-808. http://dx.doi.org/10.1093/cercor/bhh181

[36] Khum, C.M., Butler, S.R. and Schanbergh, S.M. (1978) Selective Depression of Serum Growth Hormone during Maternal Deprivation in Rat Pups. Science, 201, 1034-1036. http://dx.doi.org/10.1126/science.684424

[37] Evoniuk, G.E., Khun, C.M. and Schanbergh, S.M. (1979) The Effect of Tactile Stimulation on Serum Growth Hormone and Tissue Ornithine Decarboxylase Activity during Maternal Deprivation in Rat Pups. Communications in Psychopharmacology, 3, 363-370.

[38] Schanbergh, S.M., Evoniuk, G.E. and Kuhn, C.M. (1984) Tactile and Nutritional Aspects of Maternal Care: Specific 
Regulators of Neuroendocrine Function and Cellular Development. Proceedings of the Society for Experimental Biology and Medicine, 175, 135-146. http://dx.doi.org/10.3181/00379727-175-41779

[39] Aláez, C., Calvo, M.J., Obregon, M.J. and Pascual-Leone, A.M. (1992) Thyroid Hormones and 5-Deiodinase Activity in Neonatal Undernourished Rats. Endocrinology, 130, 773-779. http://dx.doi.org/10.1210/endo.130.2.1733724

[40] Ketelslegers, J.M., Maiter, D., Maes, M., Underwood, L.E. and Thissen, J.P. (1996) Nutritional Regulation of the Growth Hormone and Insulin-Like Growth-Binding Proteins. Hormone Research, 45, 252-257. http://dx.doi.org/10.1159/000184797

[41] Ayala-Moreno, R., Racotta, R., Anguiano, B., Aceves, C. and Quevedo, L. (2013) Perinatal Undernutrition Programmes Thyroid Function in the Adult Rat Offspring. British Journal of Nutrition, 110, 2207-2215. http://dx.doi.org/10.1017/S0007114513001736

[42] Walker, C.D. (1995) Effects of Chemical Sympathectomy and Maternal Separation Affect Neonatal Adrenocortical Stress Responses and Adrenal Sensitivity to ACTH. American Journal of Physiology, 268, RI281-R1288.

[43] Walker, C.D., Deschamps, S., Proulx, K., Tu, M., Salzman, C., Woodside, B., Lupien, S., Gallo-Payet, N. and Richard, D. (2004) Mother to Infant or Infant to Mother? Reciprocal Regulation of Responsiveness to Stress in Rodents and the Implications for Humans. Journal of Psychiatry Neurosciences, 29, 364-382. 
Scientific Research Publishing (SCIRP) is one of the largest Open Access journal publishers. It is currently publishing more than 200 open access, online, peer-reviewed journals covering a wide range of academic disciplines. SCIRP serves the worldwide academic communities and contributes to the progress and application of science with its publication.

Other selected journals from SCIRP are listed as below. Submit your manuscript to us via either submit@scirp.org or Online Submission Portal.
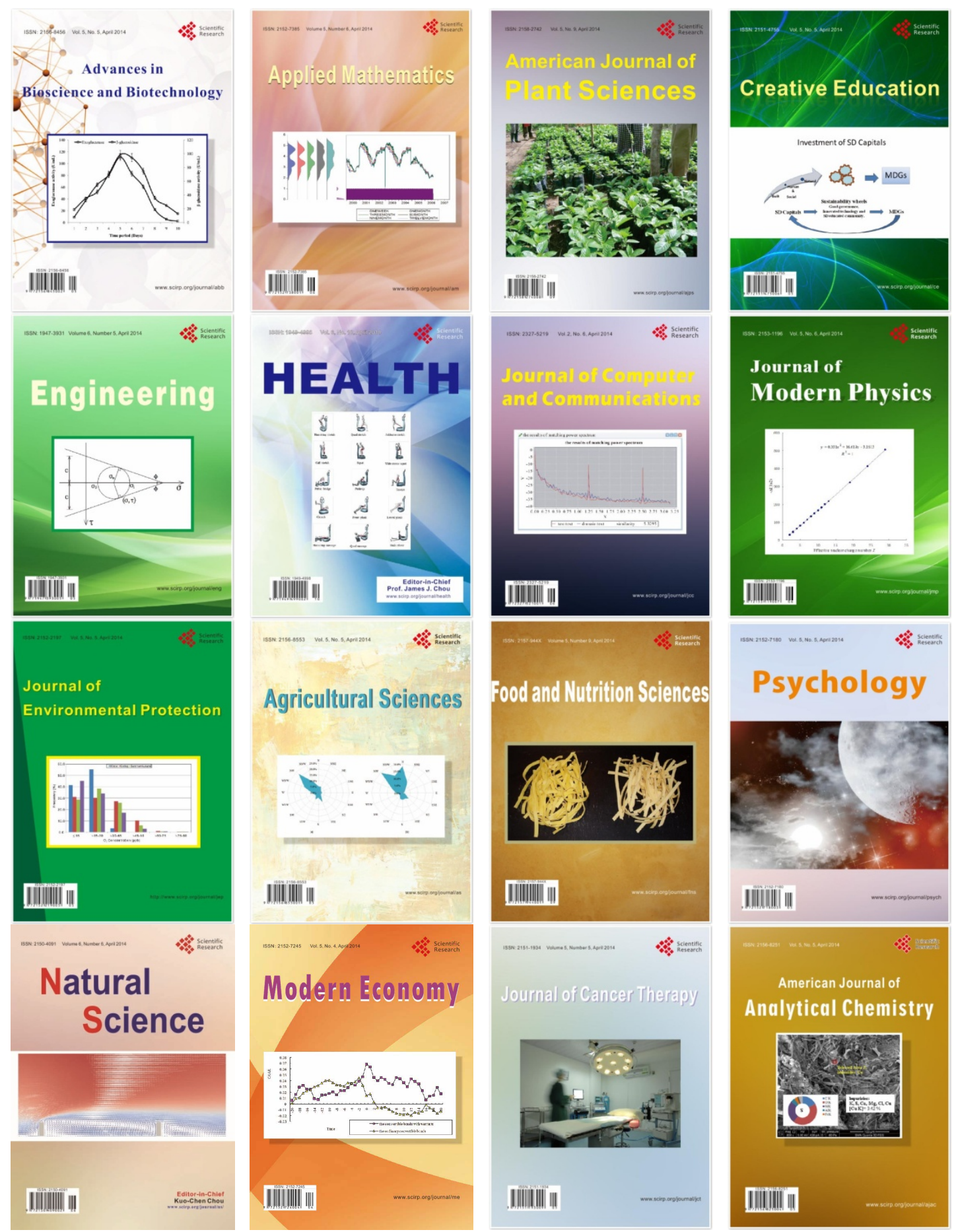